\title{
Thermodynamic Performance Assessment of Different Fluids in a Typical Organic Rankine Cycle for Usage in Municipal Solid Waste Power Plant
}

\author{
E. ÖZAhI ${ }^{a * *}$, A. TOZLU ${ }^{b}$ AND A. ABUŞOĞLU ${ }^{a}$ \\ ${ }^{a}$ University of Gaziantep, Mechanical Engineering Department, Gaziantep, Turkey \\ ${ }^{b}$ Bayburt University, Mechanical Engineering Department, Bayburt, Turkey
}

\begin{abstract}
This paper presents the energy and exergy analyses of some different organic fluids which can be used in an organic Rankine cycle adapted to a municipal solid waste power plant in the frame of energy recovery. The novelty of the study is to adapt a well-known organic Rankine cycle system theoretically to the existing municipal solid waste power plant where the exhaust gas with a temperature of almost $560{ }^{\circ} \mathrm{C}$ is sent to atmosphere causing both energy loss and air pollution, and also violating the related legislation. The efficient organic fluid that can be used in such a plant is estimated by means of the thermodynamic analyses. It is known that, in a typical municipal solid waste power plant, a considerable amount of energy is sent up from a plant chimney to the atmosphere. This waste energy can be utilized by using an adapted organic Rankine cycle system with a proper organic fluid. In this frame, some different organic fluids were examined and compared thermodynamically in this study. The optimal operation conditions of some organic fluids, R141b, isobutane, R245fa, n-pentane and n-hexane have been evaluated by means of ASPEN and EES software programs. The effects of the outlet temperature of heat source on the energetic and exergetic efficiencies and the net power output at a given pinch point temperature difference were investigated. It can be deduced from the analyses that n-hexane has the highest energetic and exergetic efficiencies at all outlet temperatures of the heat source such as $8.92 \%$ and $34.47 \%$ at $82.08^{\circ} \mathrm{C}$, respectively. It can also be stated that the maximum net power output is obtained by using the organic fluid $n$-hexane.
\end{abstract}

DOI: $10.12693 /$ APhysPolA.132.807

PACS/topics: organic Rankine cycle, waste to energy, energy and exergy analyses

\section{Introduction}

Organic Rankine cycle (ORC) is a low grade thermal energy recovery technology due to its small scale feature from geothermal energy, solar energy, biomass energy to especially waste heat energy. Municipal solid waste (MSW) can be returned into an opportunity for a sustainable production of energy which is known as "wasteto-energy" (WTE). The details in MSW technology can be found in [1].

There are many studies in ORC research field to evaluate effective parameters on its performance. Energy and exergy analyses of a waste heat driven ORC were performed by Kaşka [2] considering the performance of the cycle and pinpoint sites by means of actual data. In most studies, energetic and exergetic efficiencies of typical ORC systems with a variety of organic fluids were examined [3-6]. In this research field, another important parameter which affects the performance of a system is estimated as the outlet temperature of heat source. Many ORC systems based on the heat source temperature domain for the thermal efficiency, the exergy destruction rate and the mass flow rate were investigated by $\mathrm{Li}$ [7]. A thermo-economic methodology was performed by Desai and Bandyopadhyay [8] in order to compare organic and

*corresponding author; e-mail: ozahi@gantep.edu.tr steam Rankine cycles. Some researchers focused on the selection of proper and more effective working fluids [912]. There are also many studies on thermodynamic analyses of similar energy conversion systems [13-17].

In this paper, an ORC system which is theoretically adapted to the existing MSW power plant is analyzed thermodynamically. Energetic and exergetic efficiencies of the ORC system are evaluated in the frame of energy recovery with five different organic fluids using ASPEN and EES programs at an evaluated pinch-point temperature difference, $\Delta T_{p p}=7^{\circ} \mathrm{C}$.

\section{System description and thermodynamic analyses}

An ORC system is analyzed in this study as an alternative energy recovery system adapted to a MSW power plant (GMSWPP) which has 5.66 MW installed power in Gaziantep considering the potential energy production from the exhaust gas by using five different organic working fluids. In GMSWPP, the landfill gas (LFG) is created during the anaerobic decomposition of organic substances in MSW, industrial, and medical wastes. Unfortunately, the exhaust gas with a high temperature of approximately $560^{\circ} \mathrm{C}$ is sent to the atmosphere, which results in both energy loss and air pollution. According to the related legislation, the exhaust gas can be sent to the atmosphere with a temperature up to $60^{\circ} \mathrm{C}$. For this reason, an ORC system which is given in Fig. 1 is 
modelled and adapted theoretically to the existing GMSWPP using ASPEN software program. The organic fluids are selected as R141b, isobutane, R245fa, n-pentane and n-hexane (Table I). The energetic and the exergetic efficiencies through the adapted system are evaluated using the following equations:

$$
\begin{aligned}
& \eta_{t h}=\dot{W}_{\text {net }} / \dot{Q}_{H}, \\
& \varepsilon=\left(\dot{W}_{n e t}+E \dot{x}_{\text {out }}\right) / E \dot{x}_{\text {in }},
\end{aligned}
$$

where $\eta_{t h}$ and $\varepsilon$ are the energetic and exergetic efficiencies of the ORC system, respectively, $\dot{W}_{n e t}$ is the net power output, $\dot{Q}_{H}$ is the heat transfer rate to the evaporator, $E \dot{x}_{\text {in }}$ and $E \dot{x}_{\text {out }}$ are the exergy rate of all inputs and outputs through the system, respectively.

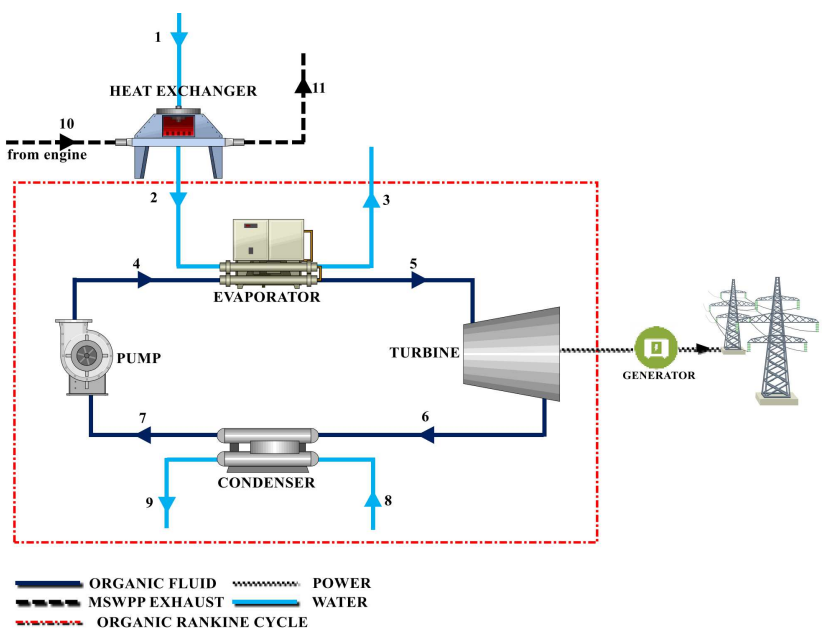

Fig. 1. Organic Rankine cycle model adapted to a municipal solid waste power plant.

TABLE I

\begin{tabular}{|c|c|c|c|c|c|c|}
\hline $\begin{array}{c}\text { Organic } \\
\text { fluid }\end{array}$ & $\begin{array}{c}\text { Mol. wt. } \\
{[\mathrm{g} / \mathrm{mol}]}\end{array}$ & $\begin{array}{l}P_{\text {crit }} \\
\text { [bar] }\end{array}$ & $\begin{array}{l}T_{\text {crit }} \\
{\left[{ }^{\circ} \mathrm{C}\right]}\end{array}$ & ALT & $\begin{array}{c}\text { ODP } \\
{[y]}\end{array}$ & $\begin{array}{c}\text { GWP } \\
{[100 y]}\end{array}$ \\
\hline R141b & 116.9 & 44.6 & 206.81 & 9.3 & 0.12 & 725 \\
\hline isobutane & 58.1 & 36.4 & 134.7 & $12 \pm 3$ & 0 & $\approx 20$ \\
\hline R245fa & 134 & 36 & 154.05 & 7.6 & 0 & 1030 \\
\hline n-pentane & 72.1 & 33.7 & 196.55 & $12 \pm 3$ & 0 & $\approx 20$ \\
\hline n-hexane & 86.175 & 30.34 & 234.67 & $\mathrm{n} / \mathrm{a}$ & $\mathrm{n} / \mathrm{a}$ & $\mathrm{n} / \mathrm{a}$ \\
\hline
\end{tabular}

Technical data of organic fluids.

In this study, the aim is to investigate both the performance of the organic fluids in the ORC systems at constant heat available and also the influences of the mass flow rate of the organic fluids for each one. The operating conditions of the ORC system are tabulated in Table II. The thermodynamic analyses performed for each subcomponent of the ORC system are tabulated in Table III.

Operating parameters of the ORC system.

TABLE II

\begin{tabular}{l|c}
\hline \hline \multicolumn{1}{c|}{ Parameter } & Value \\
\hline inlet temperature of heat source $\left[{ }^{\circ} \mathrm{C}\right], T_{h s, \text { in }}$ & 90 \\
outlet temperature of heat source $\left[{ }^{\circ} \mathrm{C}\right], T_{h s, \text { out }}$ & $46.65-82.08$ \\
mass flow rate of heat source $[\mathrm{kg} / \mathrm{s}], \dot{m} \dot{m}_{h s}$ & 16 \\
evaporating temperature $\left[{ }^{\circ} \mathrm{C}\right], T_{\text {evp }}$ & $46.65-82.08$ \\
condensing temperature $\left[{ }^{\circ} \mathrm{C}\right], T_{c o n}$ & $35.91-51.94$ \\
isentropic efficiency of pump, $\eta_{p u m p, s}$ & 0.75 \\
isentropic efficiency of turbine, $\eta_{t, s}$ & 0.75 \\
inlet temperature of cooling water $\left[{ }^{\circ} \mathrm{C}\right], T_{c w, i n}$ & 20 \\
outlet temperature of cooling water $\left[{ }^{\circ} \mathrm{C}\right], T_{c w, o u t}$ & $23-27$ \\
ambient temperature $\left[{ }^{\circ} \mathrm{C}\right], T_{a m b}$ & 20
\end{tabular}

TABLE III

\begin{tabular}{|c|c|c|}
\hline $\begin{array}{c}\text { heat } \\
\text { exchanger }\end{array}$ & $\rightarrow-\prod_{i=1}^{10}$ & $\begin{array}{l}\dot{m}_{1}=\dot{m}_{2}=\dot{m}_{w}, \dot{m}_{10}=\dot{m}_{11}=\dot{m}_{\text {exhaust }} \\
\dot{m}_{10}\left(h_{10}-h_{11}\right)=\dot{m}_{1}\left(h_{2}-h_{1}\right) \\
E_{d, h e}=\dot{m}_{10}\left(\psi_{10}-\psi_{11}\right)-\dot{m}_{1}\left(\psi_{2}-\psi_{1}\right) \\
\varepsilon_{h e}=\frac{\dot{m}_{1}\left(\psi_{2}-\psi_{1}\right)}{\dot{m}_{10}\left(\psi_{10}-\psi_{11}\right)}\end{array}$ \\
\hline evaporator & $\stackrel{5}{+}$ & $\begin{array}{l}\dot{m}_{2}=\dot{m}_{3}=\dot{m}_{w}, \dot{m}_{4}=\dot{m}_{5}=\dot{m}_{o f} \\
\dot{m}_{4}\left(h_{4}-h_{5}\right)=\dot{m}_{2}\left(h_{3}-h_{2}\right) \\
E_{d, \text { evp }}=\dot{m}_{4}\left(\psi_{4}-\psi_{5}\right)-\dot{m}_{2}\left(\psi_{3}-\psi_{2}\right) \\
\varepsilon_{\text {evp }}=\frac{\dot{m}_{2}\left(\psi_{3}-\psi_{2}\right)}{\dot{m}_{6}\left(\psi_{4}-\psi_{5}\right)}\end{array}$ \\
\hline turbine & $\stackrel{6}{4}$ & $\begin{array}{l}\dot{m}_{5}=\dot{m}_{6}=\dot{m}_{o f} \\
W_{o u t}=W_{t u r b, a c t}=\dot{m}_{5}\left(h_{5}-h_{6}\right) \\
W_{\text {out }}=W_{t u r b, r e v}=\dot{m}_{5}\left(\psi_{5}-\psi_{6}\right) \\
E_{d, t}=W_{t, \text { rev }}-W_{t, a} \quad \varepsilon_{t}=\frac{W_{t, a}}{W_{t, \text { rev }}}\end{array}$ \\
\hline condenser & & $\begin{array}{l}\dot{m}_{6}=\dot{m}_{7}=\dot{m}_{o f}, \dot{m}_{8}=\dot{m}_{9}=\dot{m}_{w} \\
\dot{m}_{6}\left(h_{6}-h_{7}\right)=\dot{m}_{8}\left(h_{9}-h_{8}\right) \\
E_{d, \text { con }}=\dot{m}_{6}\left(\psi_{6}-\psi_{7}\right)-\dot{m}_{8}\left(\psi_{9}-\psi_{8}\right) \\
\varepsilon_{c o n}=\frac{\dot{m}_{8}\left(\psi_{9}-\psi_{8}\right)}{\dot{m}_{6}\left(\psi_{6}-\psi_{7}\right)}\end{array}$ \\
\hline pump & & $\begin{array}{l}\dot{m}_{4}=\dot{m}_{7}=\dot{m}_{o f} \\
W_{\text {in }}=W_{\text {pump }, a}=\dot{m}_{4}\left(h_{4}-h_{7}\right) \\
W_{\text {in }}=W_{\text {pump,rev }}=\dot{m}_{15}\left(\psi_{4}-\psi_{7}\right) \\
E_{d, \text { pump }}=W_{\text {pump }, a}-W_{\text {pump }, \text { rev }} \\
\varepsilon_{\text {pump }}=\frac{W_{\text {pump }, \text { rev }}}{W_{\text {pump }, a}}\end{array}$ \\
\hline
\end{tabular}

Thermodynamic analyses of each subcomponent in ORC.

\section{Results and discussion}

In this paper, the effect of the outlet temperature of the heat source on the net power output, the energetic, and the exergetic efficiencies is investigated at the evaluated pinch-point temperature difference of $\Delta T_{p p}=7{ }^{\circ} \mathrm{C}$ and the related results are compared. The main results of the systematic analyses of the ORC system with the corresponding organic working fluids are tabulated in Table IV. 
Evaluated thermodynamic data for organic fluids at $\Delta T_{p p}=7^{\circ} \mathrm{C}$.

\begin{tabular}{|c|c|c|c|c|c|c|c|c|c|c|c|}
\hline Fluid & $\begin{array}{r}\dot{Q}_{h s} \\
{[\mathrm{~kW}]}\end{array}$ & $\begin{array}{c}T_{h s} \\
{\left[{ }^{\circ} \mathrm{C}\right]} \\
\end{array}$ & $\begin{array}{l}W_{n e t} \\
{[\mathrm{~kW}]}\end{array}$ & $\begin{array}{l}\eta_{t h} \\
{[\%]}\end{array}$ & $\begin{array}{c}\varepsilon \\
{[\%]}\end{array}$ & $\begin{array}{l}P_{\text {evp }} \\
\text { [bar] }\end{array}$ & $\begin{array}{c}\dot{m}_{o f} \\
{[\mathrm{~kg} / \mathrm{s}]}\end{array}$ & $\begin{array}{c}\dot{W}_{\text {pump }} \\
{[\mathrm{kW}]}\end{array}$ & $\begin{array}{l}P_{\text {con }} \\
\text { [bar] }\end{array}$ & $\begin{array}{c}T_{t e} \\
{\left[{ }^{\circ} \mathrm{C}\right]} \\
\end{array}$ & $\begin{array}{c}I \\
{[\mathrm{~kW}]}\end{array}$ \\
\hline \multirow{8}{*}{$\mathrm{R} 141 \mathrm{~b}$} & 5448 & 46.65 & 51.8 & 0.95 & 24.25 & 1.29 & 24.14 & 1.21 & 1.11 & 36.29 & 588.73 \\
\hline & 4881 & 51.18 & 112.3 & 2.30 & 25.90 & 1.49 & 21.08 & 1.48 & 1.03 & 35.91 & 507.77 \\
\hline & 4047 & 57.82 & 161.8 & 4.00 & 28.18 & 1.83 & 16.95 & 2.54 & 0.95 & 36.04 & 395.78 \\
\hline & 3363 & 63.26 & 174.1 & 5.18 & 29.75 & 2.1 & 13.74 & 3.02 & 0.88 & 36.58 & 318.78 \\
\hline & 2667 & 68.81 & 142.6 & 5.35 & 30.63 & 2.5 & 11.02 & 2.87 & 1.08 & 42.38 & 275.69 \\
\hline & 2127 & 73.12 & 122.0 & 5.74 & 31.73 & 2.9 & 8.63 & 3.11 & 1.1 & 43.44 & 221.60 \\
\hline & 1554 & 77.66 & 99.61 & 6.41 & 32.98 & 3.05 & 6.23 & 2.62 & 1.04 & 45.46 & 160.30 \\
\hline & 999 & 82.08 & 67.62 & 6.80 & 34.01 & 3.18 & 3.93 & 1.93 & 1.04 & 48.80 & 109.81 \\
\hline \multirow{8}{*}{ isobutane } & 5448 & 46.65 & 29.86 & 0.55 & 23.93 & 4.82 & 16.59 & 1.66 & 4.48 & 37.87 & 604.54 \\
\hline & 4881 & 51.18 & 58.23 & 1.19 & 24.88 & 5.4 & 14.56 & 2.91 & 4.6 & 40.22 & 557.81 \\
\hline & 4047 & 57.82 & 98.00 & 2.42 & 26.93 & 6 & 11.53 & 5.76 & 4.3 & 42.60 & 457.19 \\
\hline & 3363 & 63.26 & 166.2 & 4.94 & 29.65 & 6 & 9.19 & 4.59 & 4.3 & 48.12 & 323.61 \\
\hline & 2667 & 68.81 & 135.6 & 5.08 & 30.54 & 9 & 7.43 & 9.63 & 4.2 & 41.89 & 279.90 \\
\hline & 2127 & 73.12 & 121.4 & 5.71 & 31.69 & 9.7 & 5.7 & 9.12 & 3.9 & 42.34 & 223.38 \\
\hline & 1554 & 77.66 & 94.65 & 6.07 & 32.88 & 10.6 & 3.99 & 9.19 & 4 & 44.84 & 165.26 \\
\hline & 999 & 82.08 & 66.78 & 6.68 & 33.99 & 9 & 2.44 & 4.87 & 3.3 & 50.34 & 110.65 \\
\hline \multirow{8}{*}{ R245fa } & 5448 & 46.65 & 57.56 & 1.06 & 24.32 & 2.46 & 28.78 & 2.88 & 2.02 & 36 & 585.35 \\
\hline & 4881 & 51.18 & 70.78 & 1.45 & 25.20 & 2.75 & 25.28 & 2.53 & 2.1 & 39.13 & 541.98 \\
\hline & 4047 & 57.82 & 98.45 & 2.25 & 26.80 & 2.7 & 21.4 & 2.14 & 1.8 & 43.35 & 463.46 \\
\hline & 3363 & 63.26 & 132.9 & 3.95 & 28.84 & 4.11 & 16.22 & 3.24 & 1.9 & 41.41 & 363.29 \\
\hline & 2667 & 68.81 & 123.6 & 4.63 & 30.30 & 4.8 & 12.49 & 3.75 & 1.9 & 43.7 & 291.90 \\
\hline & 2127 & 73.12 & 109.0 & 5.13 & 31.47 & 5.4 & 9.74 & 3.9 & 1.9 & 45.44 & 234.55 \\
\hline & 1554 & 77.66 & 86.33 & 5.56 & 32.71 & 6.1 & 6.96 & 3.48 & 1.9 & 47.24 & 173.58 \\
\hline & 999 & 82.08 & 71.29 & 7.14 & 34.06 & 6.65 & 4.37 & 3.06 & 1.5 & 45.57 & 107.34 \\
\hline \multirow{8}{*}{ n-pentane } & 5448 & 46.65 & 67.33 & 1.24 & 24.52 & 1.13 & 14.76 & 0.59 & 0.93 & 36.45 & 575.58 \\
\hline & 4881 & 51.18 & 110.1 & 2.25 & 25.88 & 1.27 & 12.88 & 0.64 & 0.884 & 38.13 & 508.71 \\
\hline & 4047 & 57.82 & 130.8 & 3.23 & 27.64 & 1.45 & 10.24 & 0.2 & 0.85 & 41.99 & 422.23 \\
\hline & 3363 & 63.26 & 174.2 & 5.20 & 29.75 & 1.9 & 8.26 & 1.63 & 0.78 & 41.4 & 318.72 \\
\hline & 2667 & 68.81 & 153.7 & 5.76 & 30.87 & 2.21 & 6.35 & 1.77 & 0.8 & 44.71 & 264.01 \\
\hline & 2127 & 73.12 & 127.3 & 5.97 & 31.70 & 2 & 4.92 & 1.37 & 0.7 & 48.7 & 223.32 \\
\hline & 1554 & 77.66 & 98.59 & 6.34 & 32.96 & 2.1 & 3.51 & 1.14 & 0.68 & 51.94 & 161.33 \\
\hline & 999 & 82.08 & 76.91 & 7.70 & 34.17 & 2.65 & 2.21 & 1.17 & 0.65 & 51.51 & 101.73 \\
\hline \multirow{8}{*}{ n-hexane } & 5448 & 46.65 & 64.71 & 1.19 & 24.46 & 0.365 & 14.74 & 0.15 & 0.295 & 36.84 & 578.20 \\
\hline & 4881 & 51.18 & 121.5 & 2.49 & 26.26 & 0.437 & 12.82 & 0.26 & 0.275 & 38.07 & 490.19 \\
\hline & 4047 & 57.82 & 153.5 & 3.79 & 27.98 & 0.54 & 10.20 & 0.47 & 0.26 & 41.14 & 405.69 \\
\hline & 3363 & 63.26 & 180.8 & 5.38 & 29.81 & 0.67 & 8.21 & 0.55 & 0.233 & 42.26 & 316.10 \\
\hline & 2667 & 68.81 & 174.6 & 6.55 & 31.30 & 0.807 & 6.3 & 0.62 & 0.217 & 44.33 & 242.69 \\
\hline & 2127 & 73.12 & 155.9 & 7.33 & 32.33 & 0.926 & 4.91 & 0.63 & 0.205 & 46.01 & 192.24 \\
\hline & 1554 & 77.66 & 126.4 & 8.13 & 33.53 & 1.07 & 3.5 & 0.62 & 0.195 & 47.9 & 133.21 \\
\hline & 999 & 82.08 & 89.14 & 8.92 & 34.47 & 1.225 & 2.2 & 0.78 & 0.182 & 49.54 & 86.97 \\
\hline
\end{tabular}

\subsection{Net power output and heat available}

Figure 2 shows the effect of the outlet temperature of the heat source, $T_{h s}$ on the net power output and the heat available for using n-hexane as an organic fluid at $\Delta T_{p p}=7^{\circ} \mathrm{C}$. It is obviously seen that high amount of heat available does not support high amount of net power output. The net power output is firstly increased and then begins to decrease while the heat available decreases. This behavior of the net power output versus the outlet temperature of the heat source is observed for other organic fluids. The maximum net power output is obtained at $T_{h s}=63.26^{\circ} \mathrm{C}$.

The variations of the net power output of ORC for five different working fluids at $\Delta T_{p p}=7^{\circ} \mathrm{C}$ are given in Fig. 3. Almost same parabolic relations between the 


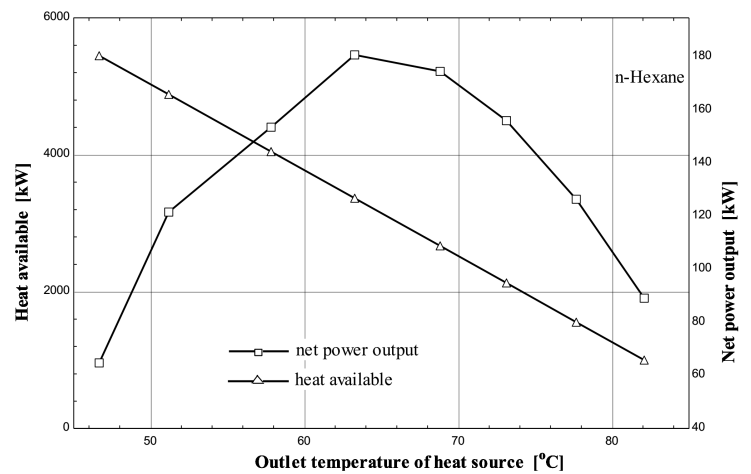

Fig. 2. Effect of outlet temperature of heat source on net power output and heat available at $\Delta T_{p p}=7^{\circ} \mathrm{C}$.

outlet temperature of the heat source and the net power output are observed for all organic fluids. It can be seen from Fig. 3 that the net power output is increased with $T_{h s}$ until $T_{h s}=63.26^{\circ} \mathrm{C}$ and after this temperature, it begins to decrease dramatically for all organic fluids. It can be deduced that the maximum net power output is obtained when n-hexane is used as an organic fluid. On the other hand, the net power output is seen to have lowest value for isobutane as an organic fluid up to $T_{h s}=$ $63.26^{\circ} \mathrm{C}$ while the lowest value of the net power output is observed for R245fa after $T_{h s}=63.26^{\circ} \mathrm{C}$.

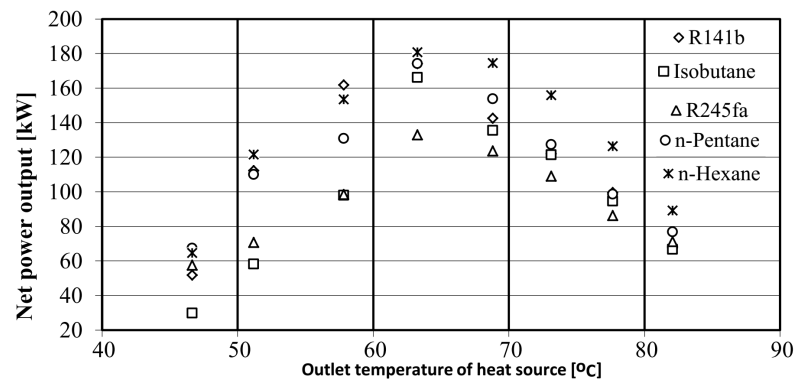

Fig. 3. Effect of outlet temperature of heat source on net power output at $\Delta T_{p p}=7{ }^{\circ} \mathrm{C}$.

\subsection{Energetic efficiency}

The effect of the outlet temperature of the heat source on the thermal efficiency, $\eta_{t h}$ of the ORC is also investigated and the relationship is given for all organic fluids in Fig. 4. For all examined organic fluids, the thermal efficiency of ORC is found to increase almost linearly with the increase of the outlet temperature of heat source. As it is well known, thermal efficiency is a function of heat available and net power output whose relations are given in Fig. 2. The thermal efficiency increases continuously although the net power output decreases after $T_{h s}=63.26^{\circ} \mathrm{C}$. This is due to the decrease in both the heat available and the net power output simultaneously at $T_{h s}>63.26{ }^{\circ} \mathrm{C}$, which results in an increase of the thermal efficiency. Then, it can be concluded that higher thermal efficiency does not always mean more net power output.

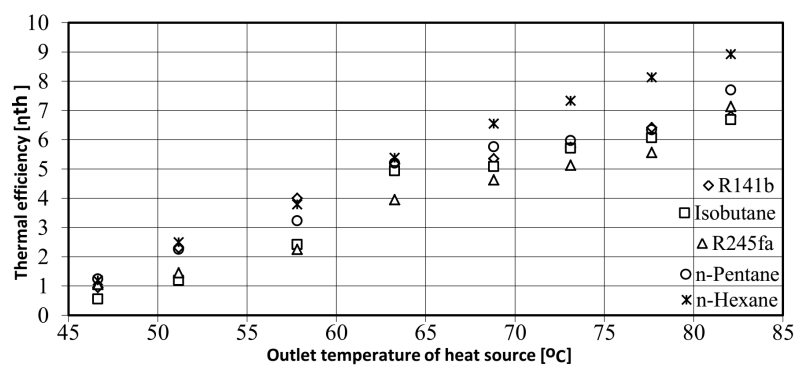

Fig. 4. Effect of outlet temperature of heat source on thermal efficiency at $\Delta T_{p p}=7^{\circ} \mathrm{C}$.

\subsection{Mass flow rate}

The influence of the outlet temperature of heat source, $T_{h s}$ on the mass flow rate of organic fluids, $m_{o f}$ is also examined and the relationship between them is illustrated in Fig. 5. With the same amount of heat input, R245fa has maximum mass flow rate in comparison with other organic fluids while n-hexane and n-pentane have minimum values. It is obviously indicated that the mass flow rate of any working fluid decreases linearly with the increase of the outlet temperature of the heat source. Meanwhile, the values of the mass flow rates of the organic fluids converge when the outlet temperature of the heat source increases as can be seen from the figure. This situation can be clarified with two reasons which are the declination of the heat available and the different decreasing rate of the latent heat of the organic fluids.

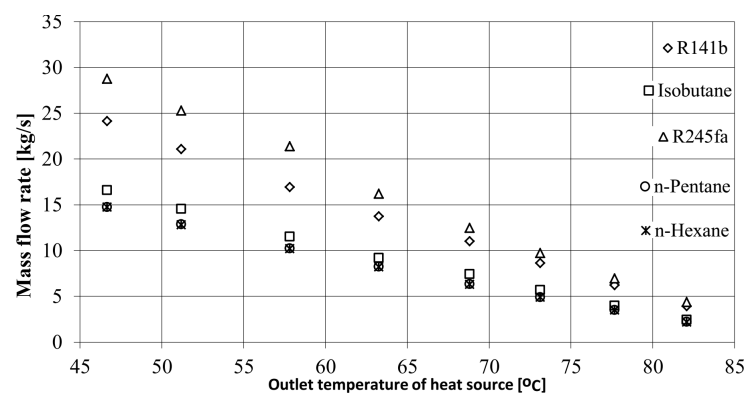

Fig. 5. Effect of outlet temperature of heat source on mass flow rate at $\Delta T_{p p}=7^{\circ} \mathrm{C}$.

\subsection{Turbine outlet temperature}

The variation of the turbine outlet temperature of the organic fluids with respect to the outlet temperature of the heat source is given in Fig. 6. As can be seen from the figure, all working fluids have almost same characteristic behavior at $\Delta T_{p p}=7{ }^{\circ} \mathrm{C}$. It is obviously said that lower slope of the relationship between them will result in more net power output.

\subsection{Exergetic efficiency}

Figure 7 shows the variation of the cycle irreversibility with respect to the outlet temperature of heat source. It can be said that the cycle irreversibilities decrease linearly with increase of the outlet temperature of the heat 


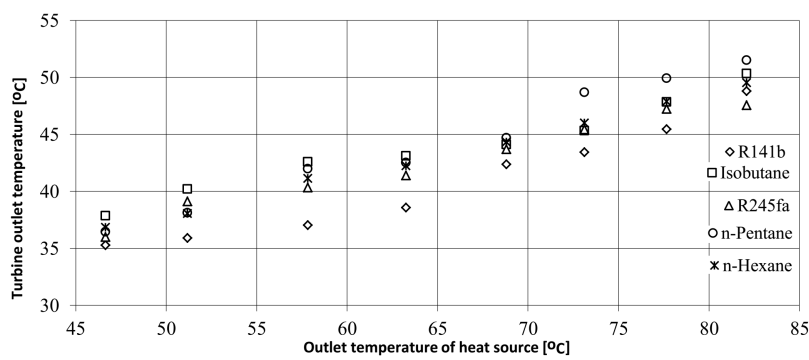

Fig. 6. Effect of outlet temperature of heat source on turbine outlet temperature at $\Delta T_{p p}=7^{\circ} \mathrm{C}$.

source for all organic fluids. Although n-hexane has the minimum cycle irreversibility, the maximum cycle irreversibility is seen for isobutane. Thus n-hexane is verified once more that it seems to be more feasible one among other organic fluids. The maximum exergy destruction occurs in the evaporator of the ORC system due to an increase in the temperature difference of the working fluids throughout the evaporator. As expected, the exergetic efficiency of the ORC system increases with increasing amount of the outlet temperature of the heat source for all organic fluids, which is illustrated in Fig. 8. Meanwhile, it is clear that n-hexane and R245fa have the maximum and the minimum exergetic efficiencies, respectively. This means that n-hexane is seen to be the best of all at the given operation conditions.

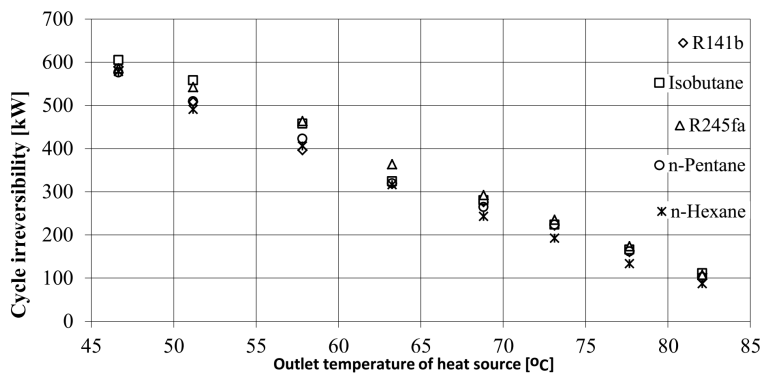

Fig. 7. Effect of outlet temperature of heat source on cycle irreversibility at $\Delta T_{p p}=7^{\circ} \mathrm{C}$.

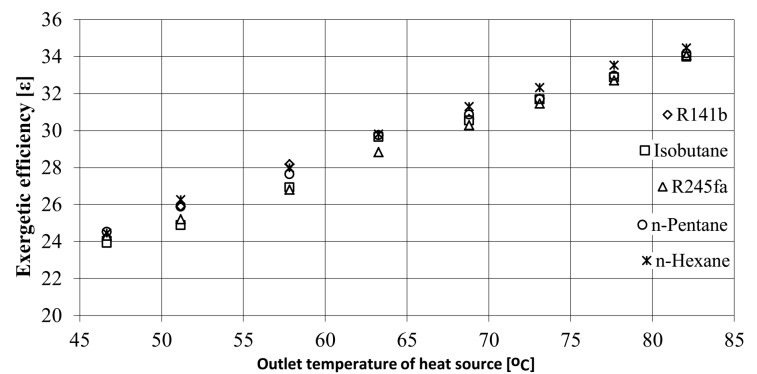

Fig. 8. Effect of outlet temperature of heat source on exergetic efficiency at $\Delta T_{p p}=7^{\circ} \mathrm{C}$.

\section{Conclusion}

A typical organic Rankine cycle within five different organic fluids is proposed and analyzed thermodynamically, which can be adapted to a municipal solid waste power plant in the frame of waste heat recovery. In this respect, systematic analyses are performed by using ASPEN Plus and EES software programs at $\Delta T_{p p}=7^{\circ} \mathrm{C}$ as a result of pinch point temperature difference analysis. As a result of the systematic analyses, the following concluding remarks can be outlined:

- High amount of heat available does not always mean high amount of net power output.

- The net power output increases with the outlet temperature of the heat source up to $T_{h s}=63.26^{\circ} \mathrm{C}$ and then, it decreases dramatically after $T_{h s}=$ $63.26^{\circ} \mathrm{C}$ for all organic fluids.

- The maximum net power output is produced from the ORC system when n-hexane is utilized as an organic fluid.

- The thermal efficiency of the ORC system is increased with an increase in the outlet temperature of the heat source.

- R245fa has maximum mass flow rate in comparison with other organic fluids while n-hexane and n-pentane have minimum values.

- The cycle irreversibility decreases linearly with the increase of the outlet temperature of the heat source for all organic fluids.

- n-hexane has the maximum exergetic efficiency while R245fa has the minimum one.

- As a result, n-hexane is found to be more feasible organic fluid among others with regard to the analyses on the net power output, the energetic and exergetic efficiencies, the cycle irreversibility and the mass flow rate in the range of the parametric study.

\section{Acknowledgments}

This study is supported by TUBİTAK (The Scientific and Technological Research Council of Turkey) with the project under the grant number of 114M142. The authors would like to thank TUBITAK and CEV (Clean Energy \& Vehicles) energy.

\section{References}

[1] A. Tozlu, E. Özahi, A. Abuşoğlu, Renew. Sustain. Energy Rev. 54, 809 (2016).

[2] Ö. Kaşka, Energy Conv. Manage. 77, 108 (2014).

[3] F. Di Maria, C. Micale, A. Sordi, Renew. Energy 66, 461 (2014).

[4] N.F.T. Özdil, M.R. Segmen, A. Tantekin, Appl. Therm. Eng. 91, 43 (2015).

[5] F. Di Maria, C. Micale, Energy Proced. 81, 272 (2015). 
[6] E. Galloni, G. Fontana, S. Staccone, Energy 90, 768 (2015).

[7] G. Li, Renew. Sustain. Energy Rev. 53, 477 (2016).

[8] N.B. Desai, S. Bandyopadhyay, Appl. Therm. Eng. 95, 471 (2016).

[9] U. Drescher, D. Brüggemann, Appl. Therm. Eng. 27, 223 (2007).

[10] D. Wang, X. Ling, H. Peng, Appl. Therm. Eng. 48, 63 (2012).

[11] D. Li, S. Zhang, G. Wang, J. Hydrodyn. 27, 458 (2015).
[12] W. Pu, C. Yue, D. Han, W. He, X. Liu, Q. Zhang, Y. Chen, Appl. Therm. Eng. 94, 221 (2016).

[13] R. Karaali, İ.T. Öztürk, Acta Phys. Pol. A 128, B279 (2015).

[14] R. Karaali, Acta Phys. Pol. A 130, 101 (2016).

[15] M. Imal, Acta Phys. Pol. A 130, 245 (2016).

[16] A.A. Jadallah, D.Y. Mahmood, Z. Er, Z.A. Abdulqaedr, Acta Phys. Pol. A 130, 434 (2016).

[17] O. Kisseleva, B. Akhmetov, P. Kharitonov, Acta Phys. Pol. A 128, B-258 (2015). 